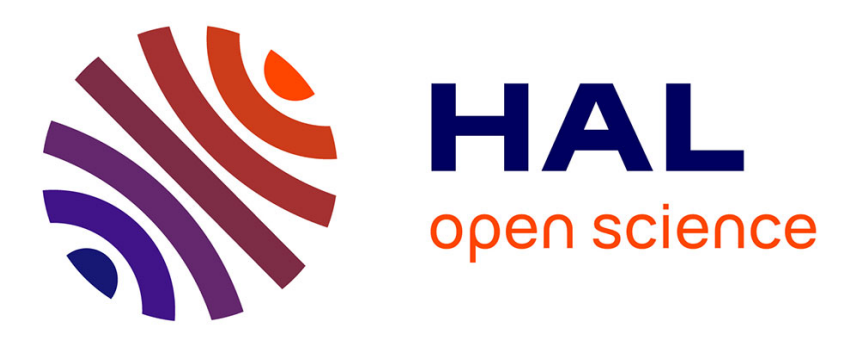

\title{
The potential of using air Jigging to sort recycled Aggregates
}

\author{
Bogdan Cazacliu, Carlos Hoffmann Sampaio, Gerson Miltzarek, Carlos Petter, \\ Laurédan Le Guen, Régis Sebben Paranhos, Florian Huchet, Ana Paula \\ Kirchheim
}

\section{To cite this version:}

Bogdan Cazacliu, Carlos Hoffmann Sampaio, Gerson Miltzarek, Carlos Petter, Laurédan Le Guen, et al. The potential of using air Jigging to sort recycled Aggregates. Journal of Cleaner Production, 2014, 1 (66), pp. 46-53. 10.1016/j.jclepro.2013.11.057 . hal-01016574

\section{HAL Id: hal-01016574 https://hal.science/hal-01016574}

Submitted on 30 Jun 2014

HAL is a multi-disciplinary open access archive for the deposit and dissemination of scientific research documents, whether they are published or not. The documents may come from teaching and research institutions in France or abroad, or from public or private research centers.
L'archive ouverte pluridisciplinaire HAL, est destinée au dépôt et à la diffusion de documents scientifiques de niveau recherche, publiés ou non, émanant des établissements d'enseignement et de recherche français ou étrangers, des laboratoires publics ou privés. 


\section{Accepted Manuscript}

The potential of using air jigging to sort recycled aggregates

Bogdan Cazacliu, Carlos Hoffmann Sampaio, Gerson Miltzarek, Carlos Petter, Lauredan Le Guen, Régis Paranhos, Florian Huchet, Ana Paula Kirchheim

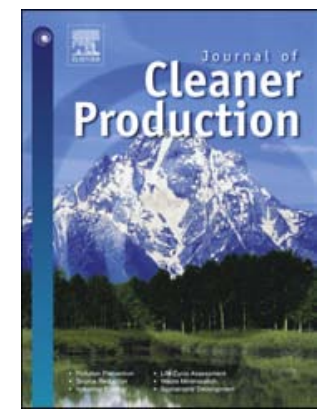

PII:

S0959-6526(13)00828-7

DOI:

10.1016/j.jclepro.2013.11.057

Reference: JCLP 3826

To appear in: Journal of Cleaner Production

Received Date: 11 June 2013

Revised Date: 14 November 2013

Accepted Date: 20 November 2013

Please cite this article as: Cazacliu B, Sampaio CH, Miltzarek G, Petter C, Le Guen L, Paranhos R, Huchet F, Kirchheim AP, The potential of using air jigging to sort recycled aggregates, Journal of Cleaner Production (2013), doi: 10.1016/j.jclepro.2013.11.057.

This is a PDF file of an unedited manuscript that has been accepted for publication. As a service to our customers we are providing this early version of the manuscript. The manuscript will undergo copyediting, typesetting, and review of the resulting proof before it is published in its final form. Please note that during the production process errors may be discovered which could affect the content, and all legal disclaimers that apply to the journal pertain. 


\section{THE POTENTIAL OF USING AIR JIGGING TO SORT RECYCLED}

\section{AGGREGATES}

Bogdan Cazacliu ${ }^{1}$ Carlos Hoffmann Sampaio ${ }^{2}$; Gerson Miltzarek ${ }^{2}$; Carlos Petter ${ }^{2}$; Lauredan Le Guen ${ }^{1}$; Régis Paranhos ${ }^{3}$; Florian Huchet ${ }^{1}$; Ana Paula Kirchheim ${ }^{4}$

${ }^{1}$ LUNAM, University of Nantes, IFSTTAR, Aggregates and Material Processing Laboratory, Nantes, France

${ }^{2}$ Federal University of Rio Grande do Sul, Center of Technology, Mineral Processing Laboratory, Porto Alegre, Brazil

${ }^{3}$ Federal University of Pampa, Mining, Planning and Mineral Processing Laboratory, LATRAM, Brazil

${ }^{4}$ Federal University of Rio Grande do Sul, Department of Civil Engineering, NORIE, Porto Alegre,

Brazil

Corresponding author: Cazacliu, Bogdan

Email: bogdan.cazacliu@ifsttar.fr

Tel: $+33 / 240845656$

IFSTTAR, Route de Bouaye - CS4

44344 Bouguenais Cedex

$\underline{\text { Abstract }}$

The recycling of inert construction and demolition materials $(C \& D)$ remains problematic if these materials are used to process high-quality recycled aggregates suitable for manufacturing new concrete. Even when selective demolition is employed, the crushing and classification of $C \& D$ produces recycled aggregates with an unacceptable level of impurities, with the content of gypsum being the biggest concern. Another concern is the percentage of brick content that decreases the density of the recycled aggregate as well as its homogeneity. The present work studies an air-jig sorting method to separate out concrete particles from a C\&D mixture that contains high amount of gypsum (22\% mass) and brick (24\% mass) particles. The mixture of aggregates studied had a 4 to $20 \mathrm{~mm}$ grading. After sorting, the bottom third of the mixture had less than $1 \%$ mass of gypsum and more than $90 \%$ mass of concrete particles. In contrast, the upper third of the sorted material contained gypsum in proportion of nearly $80 \%$ mass. The separation mechanism appears to be governed by both particle density and bulk density of individual components. These results are very encouraging and prove that the air-jigging method is a promising technology for the use in $C \& D$ recycling plants. Further research is warranted. 


\section{Highlights}

Sorting the recycled aggregates (RA) may improve the quality of this material.

Air jig prospective test on RA provided better results than previous wet jig tests.

RA resulting from the jigging are of suitable quality to be used for secondary concrete.

Both particle density and bulk density govern the separation process.

\section{$\underline{\text { Keywords }}$}

Recycled Concrete Aggregates; Gypsum; Sorting by density; Air jig; Recycled Aggregate Concrete

\section{BACKGROUND}

Construction \& Demolition materials (C\&D) is an important part of all waste generated - for instance 38\% in Australia in 2006-07 (Environment Protection and Heritage Council, 2010) - posing a severe environmental problem. Consequently, recycling of inert C\&D to complement the production of natural aggregates for the construction industry is a key in moving toward sustainability (Blengini and Garbarino, 2010). Nowadays, recycled aggregates are used to fill roads or for civil engineering infrastructures; their use in the production of new concrete is marginal (Varela et al. 2011).

A comparison of the production of $C \& D$ to the quantity of requested building aggregates given by Blengini and Garbarino (2011) demonstrates that in Europe, only around 0.8 tons/year per capita of C\&D was used versus 6 to 12 tons/year per capita of building aggregates. Clearly, current use of recycled $C \& D$ remains low. However, recycled aggregates could be used to solve perplexing disposal problems in the urban areas where unbalanced distribution of deposits has led to a serious decline in the availability of aggregates at a time of increasing demand [see Southwick et al., (2000)]. Using concrete debris from demolished infrastructure to produce new aggregates seems logical, explaining the heightened interest in using recycled concrete aggregates (RCA) in producing new generation concretes. First explore by Buck (1973), there is renewed interest in this area of research.

Industrial RCA are generally derived from a number of demolished concrete structures, contributing to large composition variability in the original concrete properties and large proportions of foreign materials (e.g., clay brick, asphalt, glass, gypsum, etc.). It is relatively easy to separate out constituents such as plastic, wood, metal, paper and roofing materials.. This is not the case for ceramics, asphalts, concrete, and stones. These components are almost always presented in different combinations of mixtures, reflecting that in practice these components are sparsely separated. Statistics from France confirm this assumption (Commissariat Général au Développement Durable, 2011); the total amount of 
23.1 Mt of C\&D (except for soil and green waste) in 2008 was composed of $17 \%$ of cement-based materials and $39 \%$ of concrete mixed with brick, asphalt and, partly with gypsum. In 2008, Varela et al. (2011) came to a similar conclusion, compiling statistics for Spain based on 0.6 million tons of marketed RCA where $70.5 \%$ of the RCA were inert mixtures and only $28.1 \%$ were identified as concrete in origin.

The recycled aggregates can be used as viable substitutes for natural aggregates in pavement subbase materials (Aatheesan et al. 2008) when composed by mixture of recycled concrete and brick rubble (Azam et Cameron, 2013)—even in cases with a significant amount of brick rubble Arulrajah et al., 2012. At opposite, the concrete produced with recycled aggregates exhibits inferior strength, and, in some cases, can have significant impact on the durability of the structures (Etxeberria et al., 2007). The presence of cement mortar attached to natural aggregates (De Juan \& Gutierrez, 2009) in the recycled concrete aggregates, the presence of clay brick particles (Yang et al., 2011) and the presence of contaminants as waste glass cullet or wood chips (Poon et Chan, 2007) have been identified as key factors that not only lower the quality of RCA but also increase the variability. Because the variability of concrete properties has direct impact in the cement consumption (Cazacliu \& Ventura, 2010), the environmental and financial balance of replacing coarse aggregate with recycled concrete aggregates may be negative, because it implies an increase of cement consumption. As a consequence, the coarse recycled concrete aggregate composition admitted for concrete production is limited by standards to mixtures of at least 90 or $95 \%$ by weight of concrete or natural stone, and having a total contaminant level typically lower than $1 \%$ of the bulk mass. In order to exclude any expansion phenomena and the damage of the microstructure in secondary concretes (Nixon, 1978), the contaminant limit is generally stricter on allowable percentages of gypsum.

Given these two issues-limitations in composition and the difficulty in extracting certain elements - the implementation of effective separation systems becomes key in RCA processing. Nowadays, the industrial practice is mostly exclusively based on the selective demolition and, in some cases, on manual sorting to avoid the mixing of different materials (PN Recybéton, 2011). Industrial practice and research studies in automatic sorting of crushed RCA are currently embryonic, as reflected in the marginal use of RCA in structural concrete. However, synergy between mineral processing and recycling of $\mathrm{C} \& \mathrm{D}$ is obvious. The potential of technological transfer points the way towards more rational use of RCAs in more friendly environmental conditions. 
Dry or wet separation processes employed in C\&D are presented in Tomas and Gröger (2000). Equipment with relatively low separation efficiency is adequate for removing lightweight impurities such as paper, wood, or plastic. Magnetic and eddy current separation is used to remove ferrous and nonferrous metals, respectively (Xing and Hendriks, 2006). More sophisticated technologies should be considered for the brick, asphalt, concrete and gypsum particles sorting, as outlined by Schnellert and Mueller (2010), who conducted experiments using wet jigging and optical sorting. Note that Ulsen et al. (2013) obtained very good results by using a heavy liquid separation technique, which is however a much more complex process.

To the best of authors' knowledge, none of these methodologies has been described in the literature for application to the sorting of recycled aggregates at the industrial scale. However, several authors have suggested that jigging be used to separate C\&D based on the densities of different materials in water as an alternative to the manual separation on a conveyor belt (EuropeAid, 2007) and as an alternative to inclined/shaking-tables or wind-sifting for particles larger than $4 \mathrm{~mm}$ (Hendriks and Xing, 2004a). Also, in a general layout sequence for a C\&D recycling plan, Coelho and de Brito (2013) proposed using a two-stage air jig, first to separate out ceramics and to separate out gypsum on RCA particles larger than $4 \mathrm{~mm}$.

Hendriks and Xing (2004b) used wet jigging in laboratory to separate out concrete and brick coarse particles, concluding that this technology works well, mainly for particles >19 mm. Finer particles $(2 \sim 5 \mathrm{~mm})$ require careful control of operating parameters to obtain good results. Müller and Wienke (2004) did not obtained good results for separating out coarse concrete and brick separation using wet jigging; however, they did obtain more promising results on the gypsum/concrete separation. In subsequent research (Schnellert et al., 2011) with industrial scale equipment showed a 4 to 5 times reduction of the gypsum content in the output material compared to the initial content.

Jigging is a stratification process based on vertical pulsation of the particles bed through the movement of a fluid (generally water). Repeated expansions (dilatation) and contractions (compression) of the particles bed promotes the stratification of the bed, which corresponds to the separation of particles in layers of increasing densities from the top to the base. Modern jigs can operate at high feed rates with good cutting accuracy in comparison to other beneficiation processes. Even if the usual medium used for stratification is water, modern jigs also use air, and the performance of these air jigs is reasonable (Sampaio et al., 2008). In general, air as a stratification medium is performed in the absence of water in 
the region, in cases where the material to be treated cannot be wetted, and, more recently, to the high environmental costs associated with the use of water (Sampaio and Tavares, 2005). Indeed, despite its relative success in separating out material, wet jigging has two disadvantages: it consumes a tremendous amount of water during the process and soaks the sorted aggregates, complicating the concrete manufacturing.

This paper investigates using air jigging in construction and demolition inert waste processing. An experiment is carried out on a model sample conditioned from crushed concrete, brick, and gypsum. The efficacy of this process is discussed, along with a recommendation for using this technique in the manufacture of new concrete.

\section{EXPERIMENTAL}

\subsection{Materials}

The material tested was manufactured from a recomposed mixture of aggregates obtained by separately crushing concrete, clay bricks, and gypsum. These constituents were obtained from concrete laboratory compressive cylinders with compressive strength of $30 \mathrm{MPa}$ at 28 days, from solid clay bricks, and from solid plaster blocks. Each individual component was comminuted at $-20 \mathrm{~mm}$ with a laboratory jaw crusher. The materials were than sieved to separate out the particle fraction to obtain particles 4 to 20 . The 4/20 $\mathrm{mm}$ fraction is typical for the range of coarse aggregates used in concrete manufacturing in most European countries.

The $4 / 20$ fraction represents about $70 \%$ mass of the total crushed aggregates: $72.4 \%$ for the concrete, $70.3 \%$ for the brick, and $66.3 \%$ for the gypsum. The granularity of each type of aggregate is given in Table 1 and represented in Figure 1. Note that the concrete particle size was the finest, with a higher amount in the 4/6 fraction than the brick and gypsum particles In contrast, the brick particles were coarser, with most of the particles in the $16 / 20$ fraction.

The skeletal and enveloped density were measured on the 4/20 crushed aggregates of each constituent. To obtain the skeletal density—which takes into account the volumes of solid and the closed pores of the particles but excludes the open pores from the particles volume-a helium pycnometer (multipycnometer quantachrome) was used on some coarse particles. The enveloped density-which also takes into account the volume of the open pores to define the particles volumes-was calculated by weighting and by water volume displacement after surface impermeabilization, as shown in Table 2 . 
Table 1 - Size distribution of the materials used for the sorting tests. The fraction $0 / 4.75 \mathrm{~mm}$ was discarded.

\begin{tabular}{|l|l|l|l|}
\hline Material & Concrete & Brick & Gypsum \\
\hline Fraction & Mass $(\%)$ & Mass & Mass \\
$(\%)$ & $(\%)$ \\
\hline $15.9 / 19.1$ & 3.9 & 12.6 & 3.6 \\
\hline $9.5 / 15.9$ & 38.6 & 43.2 & 46.4 \\
\hline $6.35 / 9.5$ & 28.8 & 31.0 & 38.1 \\
\hline $4.75 / 6.35$ & 28.7 & 13.2 & 11.9 \\
\hline Total & 100 & 100 & 100 \\
\hline
\end{tabular}

Table 2 - Skeletal and enveloped density of the materials.

\begin{tabular}{|ccc|}
\hline Material & Skeletal Density $\left(\mathrm{g} / \mathrm{cm}^{3}\right)$ & Enveloped Density $\left(\mathrm{g} / \mathrm{cm}^{3}\right)$ \\
Concrete & 2.67 & 2.39 \\
Brick & 2.59 & 2.26 \\
Gypsum & 2.30 & 1.86 \\
\hline
\end{tabular}

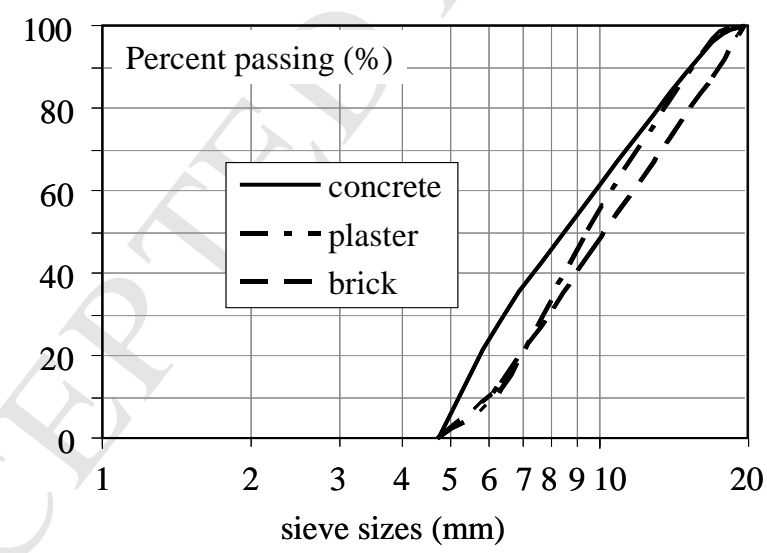

Figure 1. Grading of the three types of particles used in the sorting tests.

The tested mixture has a total mass of $39.6 \mathrm{~kg}$. The mixture was composed of $54 \%$ crushed concrete, $24 \%$ bricks particles, and $22 \%$ of gypsum (mass ratios).

\subsection{Equipment}

An air jig model AllJig S $400^{\circledR}$ was used to perform the sorting test (see Figure 2). The jig is composed of two inputs of the air flow at the bottom of the jig. The two streams of air enter the machine simultaneously. The first air flow is responsible for the expansion of the particles bed to be stratified; the 
second flow vibrates the particle bed. The air jig is assembled by different parallelepipedic boxes (without bottom) one over the other (see Figure 3), where particles are stratified during the tests. The dimension of each box is $500 \times 500 \times 50 \mathrm{~mm}^{3}$.
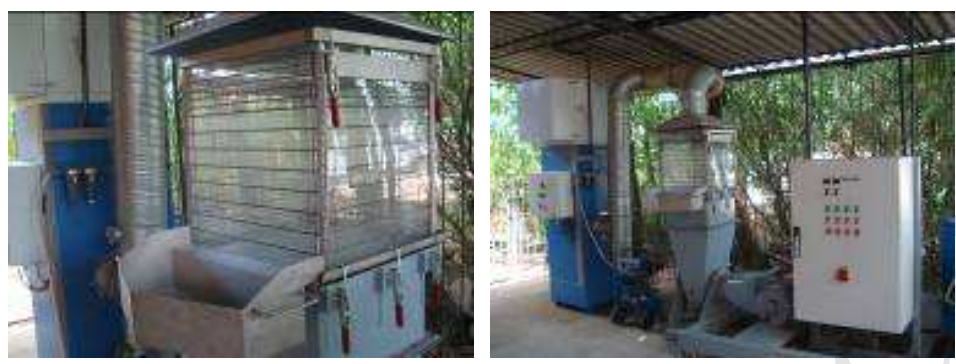

Figure 2 - AllJig S $400^{\circledR}$ jig used in the tests.
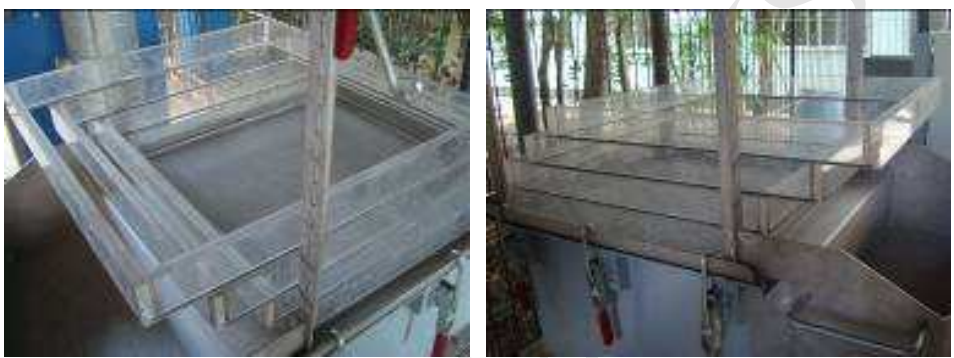

Figure 3 - Different boxes where the particles were stratified.

The air flow is generally measured via a percentage of the motor power and can be set at different ratios ( 0 to $100 \%$ ). In addition, the frequency of the cyclical air flow can be set from 0 to $190 \mathrm{~Hz}$. Finally, the time of the sorting operation can be varied from several seconds to several minutes.

\subsection{Method}

First the three boxes were assembled to constitute the test sample. The bottom box was completely filled with concrete particles, the middle box filled with brick particles, and the upper box filled with gypsum particles. This protocol was chosen as an effective way to control the proportioning of the three constituents; in the present case, each individual granular material had the same bulk volume. Five other boxes were superposed on the top of the first three boxes to accommodate the expansion of the aggregates during the test. Before the test, the three granular components were mixed manually, as shown in Figure 4a.

Once the sample was prepared, the test was performed with the following parameters: (1) the air flow (the expansion of the layer) was fixed at $80 \%$ of the motor power; (2) the frequency of the alternative air flow was set at $150 \mathrm{~Hz}$ and (3) the sorting operation time was $180 \mathrm{~s}$. After the test, the three 
boxes containing the stratified material (see Figure $4 \mathrm{~b}$ ) were removed separately. In each box, concrete, gypsum, and brick particles were separated by hand (due to their different color) and weighed to get the percentage of each component in each box.

Because the jig walls were transparent, it was possible to determine the color of the particles situated near the walls and the total volume occupied by the particles during jigging. As one wall of the jig was filmed throughout the duration of the jigging process, the evolution of the mixture composition near the wall could be estimated by using image processing. In this operation, two appropriate thresholds were chosen to determine the concrete, brick, and gypsum composition at different segregation times.

Complimentary filming of the process facilitated determining the expansion cycles of the granular material.

\section{RESULTS}

\subsection{Process evolution}

Figure 4a shows that at the beginning of the test, the concrete, brick, and gypsum particles were distributed along the height of the sample. During the jigging process, visual observation of the particles distribution on the transparent wall indicated that the sample began to segregate and that the gypsum particles (which were white in color) began accumulating on the upper part of the sample. Qualitatively, the three components were segregated after the jigging test, as shown in Figure 4b. This is also confirmed by observing the material collected in the upper part of each of the three boxes after the jigging, see Figure 5. The upper part of the upper box is mainly composed of white gypsum particles, with only some visible red brick particles. The upper part of the middle box is a mixture of red brick and grey concrete particles, with only few white gypsum particles. The upper part of the bottom box is mainly composed of concrete particles, mixed with a small proportion of clay brick elements; the white particles (the gypsum samples) are very rare.

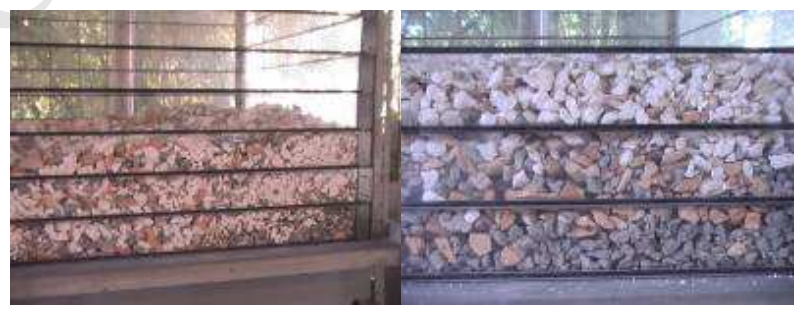

$\mathrm{b}$

Figure 4 - (a) Beginning of the test with the particles having been mixed together; and (b) end of the test where it is clear that the particles have been stratified according to density. 


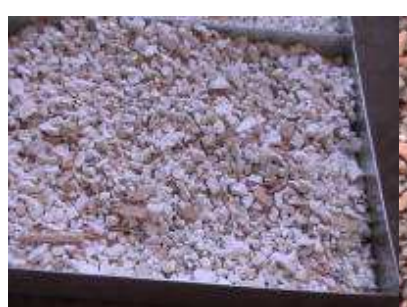

a

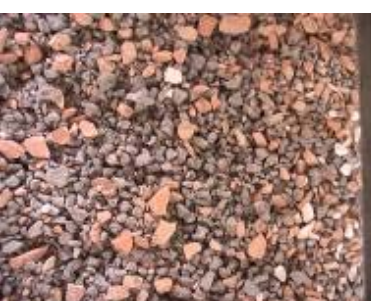

b

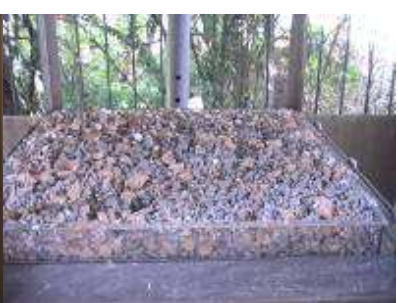

c

Figure 5 - (a) Material accumulated from the top box; (b) material accumulated in the middle box; and (c) material accumulated in the box close to the bottom.

Images taken through the transparent wall during the process are presented in the Figures 6 and

7. Once the vibratory air flow began, the mixed material made small cycles of expansion. About $12 \mathrm{~s}$ was needed to achieve a regular expansion cycle with increased amplitude. In the subsequent $8 \mathrm{~s}$, the expansion cycles were very regular at a frequency of $3.5 \mathrm{~Hz}$. The maximum expansion rate was roughly $30 \%$ (see Figure 6). Subsequently, a beat phenomena occurred and during this stage and the expansion frequency increased slightly.

The initial sorting time was set at the beginning of the regular expansion cycles. Given the low expansion amplitude, it is unlikely that there was a significant change in heterogeneity before this initial moment occurred.
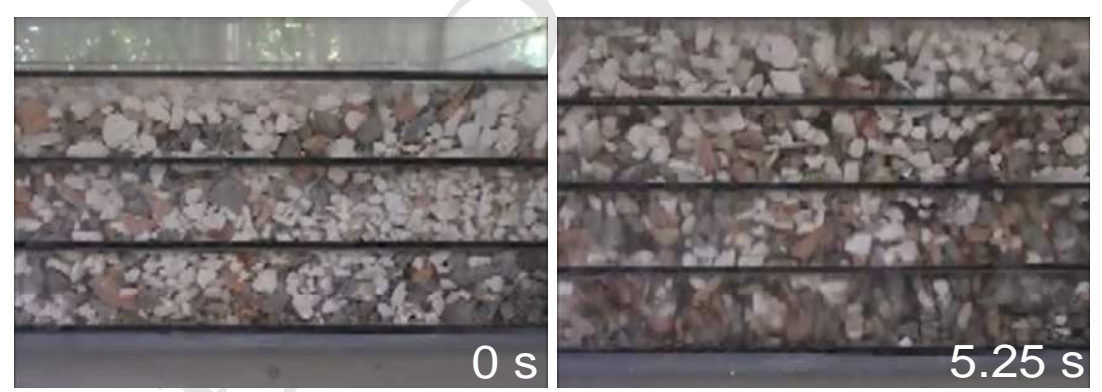

Figure 6. Observation of the particles distribution on the wall at the initial sorting time and at the maximum expansion $5.25 \mathrm{~s}$.

The emergence of beats reflects a significant change in the heterogeneity of the sample. This is confirmed by the observation of the wall in Figure 6 . At 6.8 and $8.8 \mathrm{~s}$, the proportion of gypsum in the lower layer decreased significantly. The process of segregation continued, and at 24.8 s only few gypsum particles stand in the lower layer. At the same time, the gypsum content of the middle layer also decreased. After $50 \mathrm{~s}$ the segregation state seemed to stabilize, with most gypsum remaining in the upper layer while most of the concrete had settled in the lower layer. 

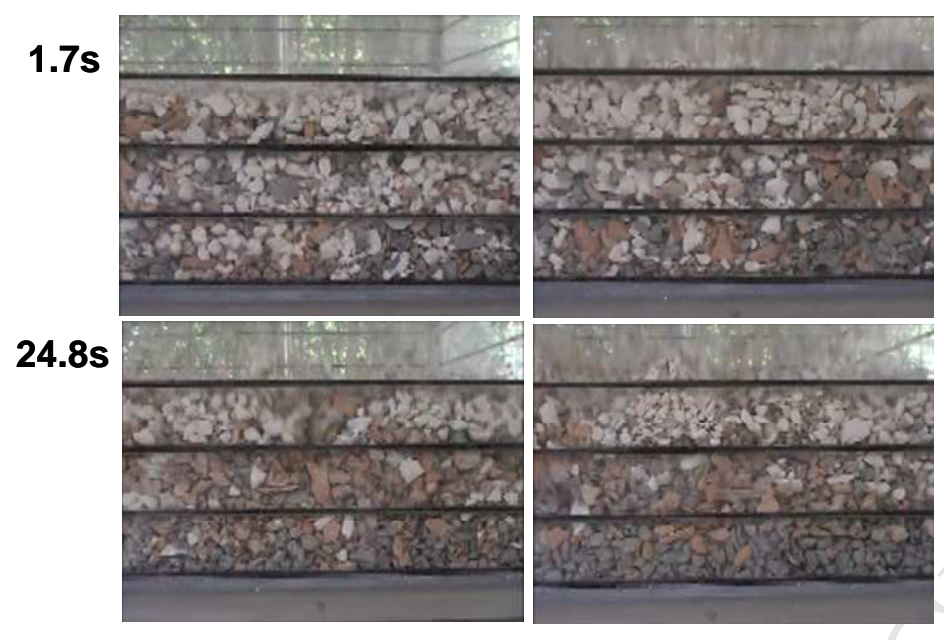

\section{$6.8 \mathrm{~s}$}

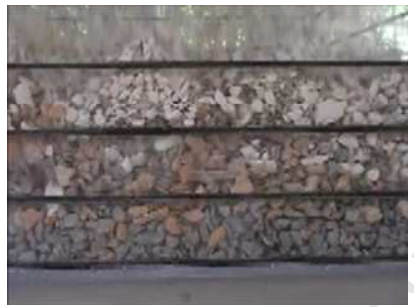

$55.7 \mathrm{~s}$

Figure 7. Sequence of observations on the wall during the sorting test

During the sorting process, the proportion of gypsum in each level box was measured by the proportion of white at the wall of the jig (see Figure 8). Note that the sorting of gypsum particles was finished after only $30 \mathrm{~s}$ of jigging. The reference time is the beginning of the expansion of particles at $19 \mathrm{~s}$ after the beginning of the test. Fifty seconds were needed to finish the operation.

An analysis of the images obtained from the wall provides key information on the percentage content of gypsum. In the beginning of the test, the three boxes were filled with more or less the same amount of gypsum (around 33.3\% in volume). This measure corresponds well with the fact that the three components of the mixture were initially mixed. At the end of the segregation, the bottom box had around $0.7 \%$ of gypsum aggregates (with a standard deviation of $0.6 \%$ ), the middle box around $9.7 \%$ of gypsum aggregates (standard deviation of $2.7 \%$ ), and the upper box $89.6 \%$ (standard deviation of $2.9 \%$ ). The mean and standard deviation values were calculated based on the images corresponding to those concentrations measured between 50 and $90 \mathrm{~s}$ of segregation. Recall that these proportions of the mixture near the jig wall are to be considered as volume ratios.

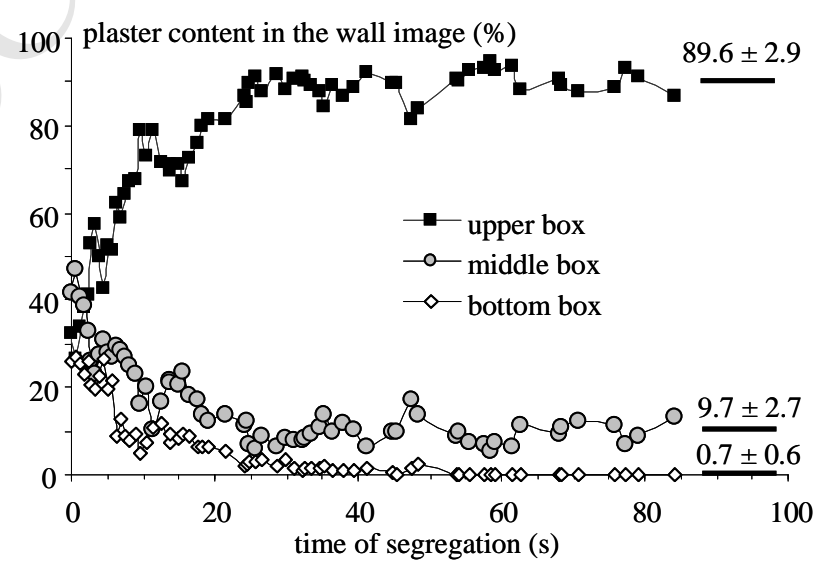


Figure 8. Evolution of gypsum content (measured by the proportion of white at the jig wall) in each layer of the probe, during the jigging process

\subsection{Final state of segregation}

Table 3 presents the measured composition in each third of the sample and the total mass of each layer at the end of the test. The content of concrete in the lower layer was $90 \%$ higher than the upper layer, while the gypsum mass content in the lower layer was less than $1 \%$. The upper layer contained a high concentration of gypsum $78.5 \%$, with a concrete content of only $3.4 \%$. The middle layer contained a majority of brick at $58.5 \%$, but the concrete and gypsum concentrations were relatively high at $30.4 \%$ and $11 \%$, respectively.

Table 3 - Results of the jigging test.

\begin{tabular}{|llllll|}
\hline Layer & Total Mass & Concrete & Brick & Gypsum \\
& $(\mathrm{kg})$ & $\%$ & \multicolumn{2}{c|}{$\%$} \\
\hline Upper & 9.15 & $3.39 \%$ & $18.06 \%$ & $78.55 \%$ \\
\hline Middle & 10.75 & $30.42 \%$ & $58.54 \%$ & $11.04 \%$ \\
\hline Lower & 19.70 & $90.68 \%$ & $8.35 \%$ & $0.97 \%$ \\
\hline
\end{tabular}

At the completion of the test, $83 \%$ of the concrete was concentrated in the lower layer, and $84 \%$ of the gypsum was concentrated in the upper layer. For both constituents, the remaining material was mostly distributed in the middle layer at $15 \%$ and $14 \%$, respectively. The brick particles in the middle layer was only $66 \%$ of the total amount, with the remaining having been distributed more or less evenly between the lower and upper layers. Basically, the procedure was able to segregate with a similar level of efficiency between concrete and brick particles, and between the brick and gypsum particles.

Good agreement was achieved between the wall image measurements and the direct measurement by weighing. When transformed in mass distribution, the wall image information indicates that the plaster content was $81.1 \% \pm 2.6 \%, 8.8 \% \pm 2.5 \%$ and $0.6 \% \pm 0.5 \%$ in the upper, middle, and bottom boxes, respectively, while weighing gave $78.6 \% 11.0 \%$, and $1 \%$, respectively.

\subsection{Governing process parameters}

In the mineral processing industry, generally a concentration criterion (CC) (Burt, 1984) is used to estimate the facility to concentrate ores:

$$
C C=\frac{\rho_{h}-\rho_{f}}{\rho_{l}-\rho_{f}}
$$


where $\rho_{h}$ is the density of heavy particles, ${ }^{\rho_{f}}$ is the density of the fluid (used in the equipment, which in this case is air), and $\rho_{l}$ is the density of lighter particles. When the $C C$ is a large number (large density difference between particles), it is easy to concentrate (by physical separation) the particles. If the $C C$ is a small number, it means that heavy and light particles have almost the same density. In that case, separation is difficult or impossible to carry out.

For the present case, the enveloped density is considered as the particle density. By using this criterion, it is easier to separate brick particles from gypsum particles $(C C=1.22)$ than it is to separate concrete from brick particles $(C C=1.06)$. As discussed earlier, this is not confirmed by the experimental results reported here, and other segregation mechanisms should be considered to verify these results taking into account the concentration criterion.

As jigging efficiency is increased by the use of coarser particles and shorter size distributions (Sampaio and Tavares, 2005), the sizing effect was considered herein. Epstein (2005) considers that for binary spheres of diameters $d_{L}$ and $d_{S}$, where $d_{L}<d_{S}$ and of density $\rho_{p}$, the driving force for segregation is given by the difference of bulk densities between of the two particle species when each is fluidized separately: $\rho_{B L}$ respectively $\rho_{B S}$. The author estimates the reduced bulk density difference $\gamma$ by:

$\gamma=\frac{\rho_{B L}-\rho_{B S}}{\rho_{p}-\rho_{f}} \approx\left(1-c_{L}\right)\left[\left(d_{L} / d_{S}\right)^{n}-1\right]$

where $\rho_{f}$ is the density of the fluid (used in the equipment, which in this case is air), $c_{L}$ is the packing density of the large particles, and $m$ - coefficient between 0.2 and 0.4 depending of the fluid flow regime.

For the present case, the reduced bulk density difference between (a) the concrete and the brick, and (b) between the brick and the gypsum is low. Indeed, the mean particle size is estimated to be 9.46 $\mathrm{mm}, 10.9 \mathrm{~mm}$, and $10.2 \mathrm{~mm}$ for the concrete, brick, and gypsum particles, respectively. The reduced bulk density difference between the concrete and the brick is less than 0.04 and between the brick and the gypsum is less than 0.02 .

However, as suggested by Escudié et al. (2006), when using non-spherical particles the driving force for segregation should consider the difference in bulk densities engendered by the difference in particle shape between the two particles species. For simplicity's sake, herein the reduced bulk density difference was calculated from the bulk densities of each individual type of aggregate simply poured in the box. Given the sample preparation procedure, it can be determined that the bulk density of each individual constituent is $1.72,0.77$ and 0.69 for the concrete, brick, and gypsum particles, respectively. 
The deduced packing densities (solid volume in a unit total volume) of the respective individual constituents are then $0.72,0.34$, and 0.37 . Note that the compaction of the concrete particles is very high, twice that of the two others constituents. The brick and gypsum particles have similar compactions.

With these values, the packing density of the mixture of particles in each layer after the sorting test can be predicted by the linear packing density model proposed by Stovall et al. (1986). In the case of a "binary mix with total interaction" (same size of the two grain populations), the mixture packing density is predicted by (de Larrard, 1999):

$c_{\text {layer }}=\frac{c_{c}}{1-\left(1-c_{c} / c_{b}\right) p_{b}}$

where $c_{\text {layer }}, c_{c}$, and $c_{b}$ are the actual packing density of the layer, individual concrete, and individual brick or gypsum, and $p_{b}$ is the volume proportion of brick and gypsum in the layer.

Because the size of the three types of particles is similar and the individual compaction of the gypsum and brick particles is quite close, this simplified equation is used to determine the layer compaction. Although other phenomena (like the recipient wall effect, different compaction indexes in the layers, etc.) have not been taken into account, the deviation of predictions from the measured values is less than 5\% (see Figure 9). This also confirms the consistency of the presented experimental results.

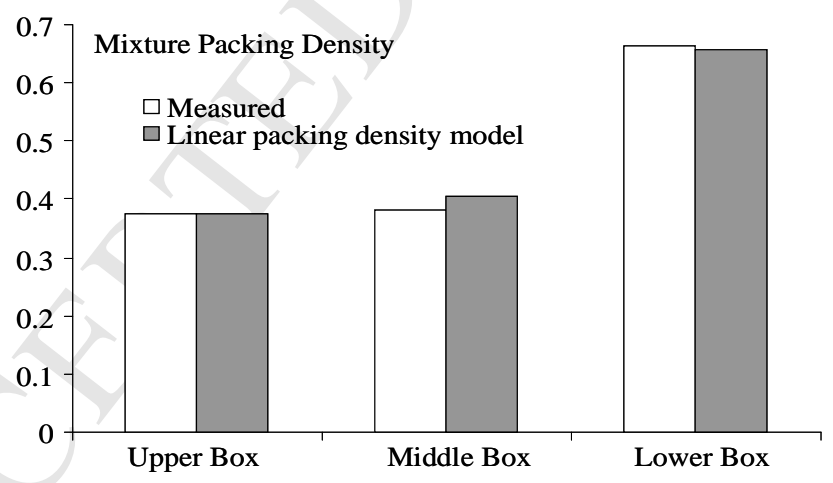

Figure 9. Comparison between the measured and predicted values of the packing density in the three layers after sorting

The reduced bulk density difference between the concrete and the brick was about 0.41 , while the reduced bulk density between the brick and the gypsum particles was less than 0.02 .

\section{DISCUSSION}

The ternary mix of concrete, brick, and gypsum particles were successfully separated using the air jig process. The composition of the non-segregated mixture in the present test is consistent with a Rc50, 
Rb30- aggregate according to the European standard EN 12620. This material is not suitable for use in concrete as the proportion of gypsum is too high and the proportion of concrete particles too low. This level of gypsum content is not even suitable to be considered appropriate for road beds.

After sorting, the content of concrete in the lower layer was $90.68 \%$ and the content of gypsum was 0.97\%. This material, classified as Rc90, Rb10-, XRg1- according to the European standard, is suitable for use in concrete with a high percentage of replacement of coarse aggregates. Indeed, the European recommendations for the use of coarse recycled coarse aggregates in concrete (European Committee for Standardization, 2012) classify this material as Type A, considered of superior quality compared to Type $\mathrm{B}$, which is also suitable for the production of concrete.

The time needed to obtain a stabilized composition is between 30 to 60 seconds. The brick was segregated from gypsum driven by the sorting mechanism, given the difference between the particles density of the two constituents. The concrete was segregated from the brick due to the sizing mechanism, as the bulk densities of the two constituents are significantly different. Note that the crushing method can impact the efficiency of the RCA sorting. Indeed, the crushing method governs the angularity and the roughness of the different components and therefore their bulk density.

Tests were carried out with material that had been crushed to particle sizes 4 to $20 \mathrm{~mm}$, which reflects the typical recycled concrete aggregates size used as fill materials in roads or civil engineering infrastructures. Note that for the present study that a considerable amount of gypsum was considered in the constituent mix in order to determine if it was possible to remove the gypsum by this sorting method. Clearly, the present air jigging sorting method provided superior results than the few previous studies, which used the wet jigging process. For instance Schnellert et al. (2011) showed that the proportion of gypsum in the final product is proportional to the proportion of gypsum in the initial material; around 5\% of gypsum was observed after sorting in a sample initially containing $20 \%$ of gypsum. Hendricks and Xing (2004b) showed good separation of concrete and brick particles for the coarsest fractions (> $19 \mathrm{~mm}$ ) but indicated the need to carefully control of operating parameters to obtain good separation result for finer fractions (for instance $2 / 5 \mathrm{~mm}$ ) even for particles relatively similar in size.

\section{CONCLUSION}

A 4/20 RCA sample composed of liberated particles of concrete, brick, and plaster was subjected to air jigging to test the efficacy of the procedure to separate out the different components. With the entry of the two air flows into the air-jig equipment, the particle bed expands and vibrates in response to the 
second inlet airflow. This movement enables the stratification of the particle bed, which presents increasing density from the top to the bottom of the equipment. Both the differences in particle density and bulk density of the three constituent materials contributed to the efficiency of the vertical sorting. The lower third of the mixture after sorting was composed of good quality recycled aggregate.

Although the substantial quantity of gypsum in the upper third of the sample demonstrates the potential to its separate recovery, the wall effect was not considered in this study. After the jigging process, gypsum particles in the lower layer could not be removed due to wall effect. These particles were close to the jig wall and did not move upwards. In industrial jigs this effect is minimized because of the width of the equipment. Despite the limitations of the current process, concentrates with higher concrete contents and rejects (lighter materials) with higher gypsum contents can certainly be reached after jigging optimization. The characterization of the air flow regime could be calibrated to obtain better control of the parameters of stratification.

The present test shows that it is possible to drastically improve the quality of recycled concrete aggregates. That said, the test is a preliminary step in refining this process. Performed on a model material comminuted from individual samples of concrete, bricks, and gypsum, no middlings (particles with different constituents) were used. Demolition materials retrieved from the field present a more difficult challenge, and it will be necessary to expand this procedure to include the presence of middling particles for physical separation.

\section{Acknowledgements}

The Capes-Cofecub Re-Maud project is acknowledged.

\section{REFERENCES}

1. Aatheesan T., Arulrajah A., Wilson J., and Bo M.W. (2008). Beneficial use of brick rubble as pavement sub-base material. In E. Ellis, H.S. Yu, G. McDowell, A. Dawson, and N. Thom (Eds.), AdvancesTransport. Geotechnics, pp. 695-699. Nottingham, England.

2. Arulrajah A., Piratheepan J., Disfani M. M., Bo M. W. (2012) Geotechnical and geoenvironmental properties of recycled construction and demolition materials in pavement subbase applications Journal of Materials in Civil Engineering, ASCE, Vol. 25, No. 8, pp. 10771088. 
3. Azam A.M., Cameron D. (2013). Geotechnical properties of blends of recycled clay masonry and recycled concrete aggregates in unbound pavement construction, J. Mater. Civil Eng., 25(6), 788-798.

4. Blengini G.A., Garbarino E. (2010). Resources and waste management in Turin (Italy): the role of recycled aggregates in the sustainable supply mix, J. Cleaner Production, 18 (10-11), 10211030.

5. Blengini G.A., Garbarino E. (2011). Synthesis report of baseline study reports (BSR-R) of SARM $\alpha$ model sites Activity 3.3 (Recycling), June 1st, 2011, 138 p. Regione Emilia-Romagna, Italy.

6. Buck A.D. (1973). Recycled Concrete, Highway Research Record, 430, pp.1-8.

7. Burt, R., 1984. Gravity concentration technology, In: Fuerstenau, D.W. (eds), Developments in Mineral Processing, vol.5, Elsevier Science, 605p. Amsterdam, Holland.

8. Cazacliu B., Ventura A. (2010). Technical and environmental effects of concrete manufacturing: dry batch versus central mixed plant, J. Cleaner Production, 18(13), 1320-1327.

9. Commissariat Général au Développement Durable (2011). Waste managed by the building companies: quantities and management methods in 2008, Chiffres et statistiques $\mathrm{n}^{\circ} 231$ Juillet 2011, 5p. Ministère de l'Ecologie du Développement Durable des Transports et du Logement, France (in French).

10. Coelho A., de Brito J. (2013). Economic viability analysis of a construction and demolition waste recycling plant in Portugal - part I: location, materials, technology and economic analysis, J. Cleaner Production, 39, 338-352.

11. De Juan M.S., Gutierrez P.A. (2009). Study on the influence of attached mortar content on the properties of recycled concrete aggregate, Construct. Build. Mater., 23 2, 872-877.

12. De Larrard F. (1999). Concrete Mixture Proportioning: A Scientific Approach, Modern Concrete Technology (Book 9) CRC Press, Taylor \& Francis, 448 p.

13. Environment Protection and Heritage Council (2010), Resource recovery and waste management in Australia today, in National Waste Report 2010, p.19-140, Australian Government.

14. EN 12620 (2011). Aggregates for concrete, European Committee for Standardization, Ref. No. FprEN 12620:2011:E.

15. Epstein N. (2005). Teetering, Powder Tech., 151(1-3), 2-14. 
16. Escudié R., Epstein N., Grace J.R., Bi H.T. (2006). Effect of particle shape on liquid-fluidized beds of binary (and ternary) solids mixtures: segregation vs mixing, Chem. Eng. Sci., 61(5), $1528-1539$.

17. Etxeberria M., Vazquez E., Mari A., Barra, M.(2007). Influence of amount of recycled coarse aggregates and production process on properties of recycled aggregate concrete, Cement Concr. Res., 37, 735-742.

18. European Committee for Standardization (2012),. Use of aggregates in concrete. TC104-SC1TG19, Sixth draft text for EN 206, September 19, 2012.

19. EuropeAid (2007). Key factors in technology identification and selection, Report, EU-ASIA PRO ECO II B Post -Tsunami Programme, Demonstrating ESTs for Building waste Reduction in Indonesia. $86 \mathrm{p}$. Malaya.

20. Hendriks C.F., Xing W. (2004a). Quality improvement of granular wastes by separation techniques. In E. Vázquez, Ch. F. Hendriks, and G.M.T. Janssen (Eds.), International RILEM Conference on the Use of Recycled Materials in Building and Structures, RILEM Publications SARL, 142-149.

21. Hendriks, C., Xing, W., (2004b). Suitable separation treatment of stony components in Construction and Demolition Waste (CDW). Proceedings, International RILEM Conference on the Use of Recycled Materials in Building and Structures, Eds. E. Vázquez, Ch. F. Hendriks, and G.M.T. Janssen, RILEM Publications SARL, 166-172.

22. Müller A., Wienke L. (2004). Measurements and models for the gravity concentration of C\&D waste through jigging, Proceedings, International RILEM Conference on the Use of Recycled Materials in Building and Structures, Eds. In E. Vázquez, Ch. F. Hendriks, and G.M.T. Janssen, RILEM Publications SARL, 115-122.

23. PN Recybéton (2011). Complete Recycling of Concrete, Feasibility Report, May 2011, 51 p. France (in French).

24. Poon C.-S., Chan D. (2007). Effects of contaminants on the properties of concrete paving blocks prepared with recycled concrete aggregates. Construct. Bldg. Mater., 21(1), 164-175.

25. Sampaio C.H., Aliaga W., Pacheco E.T., Petter E.A., Wotruba H. (2008). Coal beneficiation of Candiota mine by dry jigging. Fuel Processing Technology, 89(2), 198-202. 
26. Sampaio C.H., Tavares L.M.M. (2005). Beneficiamento Gravimétrico: Uma introdução aos processos de concentração mineral e reciclagem de materiais por densidade, ed. Editora UFRGS, 1, p.603, Porto Alegre, Brazil.

27. Schnellert T., Kehr K., Müller A. (2011). Development of a separation process for gypsumcontaminated concrete aggregates. Proceedings, 2nd International RILEM Conference on Progress of Recycling in the Built Environment, Eds. V.M. John, E. Vazquez, S.C. Angulo, and C. Ulsen, RILEM Publications SARL, 477-482.

28. Schnellert, T.; Mueller, A. 2010. Separation techniques for CDW -best practice. 22 November 2010, www.abw-recycling.de/de/barcelona.html, accessed on 25/05/2013.

29. Stoval T., de Larrard F., Bull M. (1986). Linear packing density model of grain mixtures. Powder Tech., 48, 1-12.

30. Southwick D.L., Jouseau M., Meyer G.N., Mossier J.H., Wahl T.E. (2000). Aggregate resources inventory of the seven-county metropolitan area. Minnesota Geological Survey Information Circular, 46, p. 91. Minnesota, US

31. Tomas J., Gröger T. (2000). Assessment of multistage turbulent cross-flow aeroseparation of building rubble. Developments in Mineral Processing, 13, C7-34 - C7-43.

32. Ulsen C., Kahn H., Hawlitschek G., Masini E., Angulo S. (2013). Separability studies of construction and demolition waste recycled sand. Waste Management, 33, 656-662

33. Varela E., Vazquez E., Güell A., Barra M., Girbés I., López F., Martínez M.I., Romero A., Serna P., Tirado A. (2011). Gear project - diagnosis of the current recycling situation in Spain, Proceedings, 2nd International RILEM Conference on Progress of Recycling in the Built Environment, Eds. V.M. John, E. Vazquez, S.C. Angulo, and C. Ulsen, RILEM Publications SARL, $29-38$.

34. Xing W., Hendriks C.F. (2006). Decontamination of granular wastes by mining separation techniques, J. Cleaner Production, 14(8), 748-753.

35. Yang. J., Qiang D., Yiwang B. (2011). Concrete with recycled concrete aggregate and crushed clay bricks. Construc. Bldg. Mater., 25(4), 1935-1945. 